\title{
New Keynesian Dynamics in a Low Interest Rate Environment.
}

\author{
R. Anton Braun \\ University of Tokyo \\ Lena Mareen Körber \\ German Institute for Economic Research
}

January 20, 2010

\begin{abstract}
Recent research has found that the dynamics of the New Keynesian model are very different when the nominal interest rate is zero. Positive technology shocks and negative shocks to the labor tax rate lower economic activity and the size of the government purchase multiplier can be as large as four. We consider the empirical relevance of these dynamics using Japanese data. We find that when one uses a nonlinear solution method, the qualitative properties of the model depend on the size of the shock. For moderate sized shocks the New Keynesian model exhibits orthodox dynamics and the size of the government purchase multiplier is less than one. We document that specifications with moderate shocks are most consistent with Japanese data.
\end{abstract}

Keywords: Government purchases; zero nominal interest rates; monetary policy 


\section{Introduction}

Recent research has found that the dynamics of the New Keynesian model are quite different when the nominal interest rate is zero. A reduction in the labor tax or an improvement in technology can lower output and the size of the government purchase multiplier can be much larger than one. To understand why the dynamics are so different consider the case of a positive transitory shock to technology. If monetary policy stabilizes the price level output increases. In contrast, if monetary policy follows a $\mathrm{k} \%$ money supply rule and does not respond output may fall. ${ }^{1}$ In the presence of costly price adjustment of goods the arrival of a positive technology shock today has a depressing effect on economic activity. Households realize that prices will be cheaper tomorrow and choose to defer their consumption and investment activities until the price falls. Firms experience temporarily high markups and profits.

One situation where monetary policy cannot respond to technology or any other shocks for that matter is when the nominal interest rate is zero. Braun and Waki (2006) find in this situation that output falls in response to a persistent but transitory improvement in technology using a New Keynesian model calibrated to Japanese data. Eggertsson (2009) has recently illustrated that a reduction in the labor tax can increase the markup by so much that output falls against a background of zero a nominal interest rate. Christiano, Eichenbaum and Rebelo (2009) find that the size of the government purchases multiplier is much larger than one in an environment where a shock leads the nominal interest rate to hit its lower bound of zero.

The purpose of this paper is to investigate whether these properties of the New Keynesian model are empirically relevant. We use Japan as a laboratory. Japan is interesting because it experienced zero nominal interest rates between 1999 and 2005. In this paper we provide answers to the three following questions about Japan's episode with zero nominal interest rates:

1. How big was the government purchases multiplier?

2. Would a lower labor tax have depressed economic activity?

3. Did the slowdown in the growth rate of TFP raise GNP?

The answer to the second and third questions is no.

Surprisingly, when we calibrate a prototypical New Keynesian model to Japanese data and feed through a set of shocks that reproduce Japan's experience the model does not have the properties that are the premise of the second and third questions. Instead the

\footnotetext{
${ }^{1}$ We have in mind a model with capital accumulation. See Basu and Kimball(2003) for some examples where this happens.
} 
model predicts that a lower labor tax raises GNP and also that a positive technology shock increases GNP regardless whether the zero constraint is binding.

There are several reasons for why this is the case. In our economy, the expected duration of zero nominal interest rates is short. Households expect the nominal interest rate to be zero for two years and positive afterwards. Another important reason is that the state of the economy and the set of shocks that we consider are empirically relevant in the sense that they reproduce outcomes from Japan during this period. Finally, we use exact nonlinear methods to solve the model.

In the baseline specification of our economy, the answer to the first question is less than one. The value of the government purchase multiplier ranges from 0.6 to 0.9 depending on the year when government purchases are increased and also how the experiment is defined.

If instead we use a specification where the shocks are calibrated to produce persistent expectations of five years of zero nominal interest rates then the model produces larger government purchases GNP multipliers that range from 1.1 to 1.4.

Japan's episode with zero nominal interest rates was a period in which output growth was low but it was also a period of tranquility. We use this evidence to discriminate between the two specifications of agents' expectations.

The baseline specification of expectations does well in this regard. It produces additional variability of the markup during the period of zero nominal interest rates. But the magnitude of this variability is small and the model predicts that the period of zero nominal interest rates was a period of tranquility. However, when we posit expectations of zero nominal interest rates for a period of five or more years the model predicts that the period of zero nominal interest rates was a time of macroeconomic instability and this is inconsistent with what happened in Japan.

Overall, we conclude that Japan's experience with zero interest rates is consistent with the New Keynesian model under the assumption that expectations of zero nominal interest rates were relatively short lived. Under this assumption, the New Keynesian model has orthodox implications:

1. The government purchases multiplier is less than one.

2. A lower labor tax rate increases GNP.

3. A an improvement in neutral technology also increases GNP.

Our results are related to research by Braun and Waki (2009). They analyze the role of the solution method for the size of the government purchase multiplier in two versions of the New Keynesian model that differ according to the way the costly price adjustment works. They find that linear solution methods are inaccurate in the presence of preference discount rate shocks that are 4 percent or higher and that linear solution methods can induce 
a substantial upward bias in the government purchase multiplier. For this reason we use nonlinear methods when solving for the equilibrium.

The remainder of the paper is organized as follows. Section 2 develops our analogue economy. Section 3 describes calibration and simulation method. Results are reported in section 4 and Section 5 concludes.

\section{Economy}

We consider a prototypical New Keynesian economy. The economy is populated by a representative household, a representative final good producer, a continuum of intermediate good producing monopolists that face quadratic costs of adjusting prices, a government and a central bank. We discuss the problems of these agents in turn.

\subsection{Households}

The representative household chooses sequences of consumption $\left\{c_{t}\right\}_{t=0}^{\infty}$ and leisure $\left\{1-h_{t}\right\}_{t=0}^{\infty}$ to maximize

$$
E_{0} \sum_{t=0}^{\infty} \beta^{t} \prod_{j=0}^{t} d_{j}\left\{\frac{\left(c_{t}^{\nu}\left(1-h_{t}\right)^{1-\nu}\right)^{1-\sigma}}{1-\sigma}\right\}
$$

where $c_{t}$ is consumption of the composite good and $h_{t}$ is hours worked expressed as a fraction of a time endowment of one. $\beta$ denotes the discount factor and $\nu$ is the weight a household attaches to consumption. $d_{t}$ is a shock to the subjective discount rate with the law of motion

$$
\ln \left(d_{t}\right)=\rho_{d} \ln \left(d_{t-1}\right)+\epsilon_{d, t}
$$

The household's period $t$ budget constraint is given by

$$
\begin{aligned}
& \left(1+\tau_{c, t}\right) c_{t}+x_{t}+\frac{B_{t}}{P_{t}}= \\
& \left(1+R_{t-1}\right) \frac{B_{t-1}}{P_{t}}+\int_{0}^{1} \frac{\Pi_{t}(i)}{P_{t}} d i+T_{t}+\left(1-\tau_{t, K}\right) r_{t} k_{t-1}+\left(1-\tau_{t, W}\right) w_{t} h_{t}+\tau_{t, K} \delta k_{t-1}
\end{aligned}
$$

where $P_{t}$ is the price level, $B_{t}$ is the household's holdings of nominal debt at the end of period $t, k_{t-1}$ is level of capital chosen in period $t-1$ and $x_{t}$ is investment. Households hold equal amounts of shares in each intermediate goods firm so that $\Pi_{t}(i)$ is per capita nominal profits from intermediate firm indexed $i$. Households pay taxes $\tau_{c, t}, \tau_{t, k}$ and $\tau_{t, w}$ on consumption, capital income and labour income, respectively, and receive lump-sum transfers of size $T_{t}$ from the government. 
Capital is subject to adjustment costs and is accumulated according to

$$
k_{t}=(1-\delta) k_{t-1}+x_{t}-\frac{\phi}{2}\left(\frac{x_{t}}{k_{t-1}}-\mu_{k}+1-\delta\right)^{2} k_{t-1}
$$

The optimal choices of the representative household satisfy

$$
\begin{aligned}
& \frac{\nu\left(c_{t}^{\nu}\left(1-h_{t}\right)^{1-\nu}\right)^{1-\sigma}}{c_{t}}=\lambda_{c, t}\left(1+\tau_{c, t}\right) \\
& \frac{(1-\nu)\left(c_{t}^{\nu}\left(1-h_{t}\right)^{1-\nu}\right)^{1-\sigma}}{1-h_{t}}=\lambda_{c, t}\left(1-\tau_{w, t}\right) w_{t} \\
& \lambda_{c, t}=\lambda_{k, t}\left[1-\phi\left(\frac{x_{t}}{k_{t-1}}-\mu_{k}+1-\delta\right)\right] \\
& 0=\beta E_{t} d_{t+1} \lambda_{c, t+1}\left[\left(1-\tau_{k, t+1}\right) r_{t+1}+\tau_{k, t+1} \delta\right]-\lambda_{k, t} \\
& \quad+\beta E_{t} d_{t+1} \lambda_{k, t+1}\left[1-\delta+\phi\left(\frac{x_{t+1}}{k_{t}}-\mu_{k}+1-\delta\right) \frac{x_{t+1}}{k_{t}}-\frac{\phi}{2}\left(\frac{x_{t+1}}{k_{t}}-\mu_{k}+1-\delta\right)^{2}\right] \\
& -\lambda_{c, t} / P_{t}+\beta E_{t} d_{t+1} \lambda_{c, t+1}\left(1+R_{t}\right) / P_{t+1}=0
\end{aligned}
$$

\subsection{Final Good Firm}

Perfectly competitive final good firms use a continuum of intermediate goods $i \in 0,1$ to produce a single final good that can be used for consumption and investment. The final good is produced using the following production technology

$$
y_{t}=\left(\int_{0}^{1} y_{t}(i)^{\frac{\theta-1}{\theta}} d i\right)^{\frac{\theta}{\theta-1}}
$$

The profit maximizing input demands of the final good firm are

$$
y_{t}(i)^{d}=\left(\frac{p_{t}(i)}{P_{t}}\right)^{-\theta} y_{t}
$$

where $p_{t}(i)$ denotes the price of the good produced by firm i.

\subsection{Intermediate Goods Firms}

There is a continuum of monopolistically competitive intermediate goods firms each producing one differentiated good according to the technology

$$
y_{t}(i)=k_{t-1}(i)^{\alpha}\left(A_{c, t} h_{t}(i)\right)^{(1-\alpha)}
$$


We assume that the level of technology $A_{t}$ is hit by permanent shocks $\psi_{A, t}$ and transitory shocks $\epsilon_{A, t}$. It has the law of motion

$$
\begin{aligned}
& A_{t}=Z_{A, t} e^{v_{A, t}} \\
& v_{A, t}=\rho_{A} v_{A, t-1}+\epsilon_{A, t} \\
& Z_{A, t} / Z_{A, t-1}=\mu_{A, t} \\
& \mu_{A, t}=\mu_{A} e^{\psi_{A, t}}
\end{aligned}
$$

Each intermediate firm solves a dynamic profit maximization problem that can be broken down into two parts: The choice of the cost minimizing level of inputs and the choice of the optimal sequence of prices of output. There are two inputs: labor and capital. We further assume that a subsidy $s=\theta /(\theta-1)$ is in place that corrects the static inefficiency due to monopolistic competition. This subsidy isolates the dynamic distortion caused by the variation in the markup which is the distortion that monetary policy corrects in this model. It also allows us to nest a real business cycle model as a special case by setting the adjustment costs on prices to zero.

Cost minimization implies

$$
\begin{aligned}
& r_{t}=\alpha s \chi_{t} k_{t-1}(i)^{\alpha-1}\left(A_{t} h_{t}(i)\right)^{1-\alpha} \\
& w_{t}=(1-\alpha) s \chi_{t} A_{t}^{(1-\alpha)} k_{t-1}(i)^{\alpha} h_{t}(i)^{-\alpha} \\
& \chi_{t}=\frac{r_{t}^{\alpha} w_{t}^{1-\alpha}}{\alpha^{\alpha}(1-\alpha)^{1-\alpha} A_{t}^{1-\alpha}}
\end{aligned}
$$

where $\chi_{t}$ is real marginal cost. Given the optimal choice of labor and capital, each intermediate goods firm chooses a sequence $p_{t}(i)$ to maximize profits. Price rigidity is introduced using a convex cost of price adjustment as in Rotemberg (1996). Gross inflation $1+\pi_{t}(i)$ is defined as $p_{t}(i) / p_{t-1}(i)$. Then the price setting problem of a typical intermediate goods producer is given by

$$
\sum_{t=0}^{\infty} \beta^{t} \prod_{j=0}^{t} d_{j} \lambda_{c, t}\left[p_{t}(i) y_{t}(i)-P_{t} \chi_{t} y_{t}(i)-\frac{\gamma_{0}}{2} P_{t}\left(\pi_{t}-\gamma_{1, t}\right)^{2} y_{t}\right] / P_{t}
$$

subject to (11) where $\lambda_{c, t}$ is the Lagrangian multiplier on the household's budget constraint.

The first order condition for this problem implies that the optimal sequence of prices satisfies

$$
\beta E_{t} \frac{d_{t+1} \lambda_{c, t+1} y_{t+1}}{\lambda_{c, t} y_{t}} \gamma_{0}\left(\pi_{t+1}-\gamma_{1, t+1}\right)\left(1+\pi_{t+1}\right)=-\left[1-\theta+\theta \chi_{t}-\gamma_{0}\left(\pi_{t}-\gamma_{1, t}\right)\left(1+\pi_{t}\right)\right]
$$

\subsection{Monetary Policy}

Interest rate targeting rules have been found to be good empirical specifications of monetary policy in e.g. Taylor (1993) and we refer to monetary policy rules of this form as Taylor 
rules. The particular interest rate targeting rule considered here is

$$
R_{t}=\max \left[(1+R)\left(\frac{1+\pi_{t}}{1+\pi}\right)^{\rho_{\pi}}\left(\frac{1+R_{t-1}}{1+R}\right)^{\rho_{P}} e^{u_{M, t}}-1,0\right]
$$

where $u_{M, t}$ is an I.I.D. normal random variable. One special feature of this rule is that there is zero weight on output stabilization. We are going to consider a sample period in which Japan experienced a long and persistent departure from trend growth and it is not clear how one would define the target level of output in such an environment. For this reason we limit attention to Taylor rules that target the inflation rate.

\subsection{Fiscal Policy}

The fiscal authority finances its expenditures with distortionary taxes, lump-sum transfers and nominal bonds. Fiscal policies satisfy the period budget constraint

$$
g_{t}+\left(1+R_{t-1}\right) \frac{B_{t-1}}{P_{t}}+S_{t}=\frac{B_{t}}{P_{t}}-T_{t}+\tau_{w, t} w_{t} h_{t}+\tau_{c, t} c_{t}+\tau_{k, t} k_{t-1}\left(r_{t}-\delta\right)
$$

where $S_{t}$ are subsidies to intermediate monopolists. Defining $b_{t} \equiv \frac{B_{t}}{P_{t}}$, we can rewrite the government budget constraint as

$$
g_{t}+\left(1+R_{t-1}\right) b_{t-1} \frac{1}{1+\pi_{t}}=b_{t}-T_{t}+\tau_{w, t} w_{t} h_{t}+\tau_{c, t} c_{t}+\tau_{k, t} k_{t-1}\left(r_{t}-\delta\right)
$$

The tax rates on capital, consumption and labor and government purchases have the following laws of motion

$$
\begin{aligned}
\tau_{c, t} & =\left(1-\rho_{c}\right) \tau_{c}+\rho_{c} \tau_{c, t-1}+\epsilon_{c, t} \\
\tau_{k, t} & =\left(1-\rho_{k}\right) \tau_{k}+\rho_{k} \tau_{k, t-1}+\epsilon_{k, t} \\
\tau_{w, t} & =\left(1-\rho_{w}\right) \tau_{w}+\rho_{w} \tau_{w, t-1}+\epsilon_{w, t} \\
\frac{g_{t}}{g n p_{t}} & =\left(1-\rho_{g}\right) \frac{g}{g n p}+\rho_{g} \frac{g_{t-1}}{g n p_{t-1}}+\epsilon_{w, t}
\end{aligned}
$$

where the shocks to each variable are I.I.D. normal random variables. Lump-sum taxes are assumed to adjust to satisfy the government budget constraint.

To close the model, the aggregate resource constraint is given by

$$
g_{t}+c_{t}+x_{t}=y_{t}\left(1-\frac{\gamma_{0}}{2}\left(\pi_{t}-\gamma_{1, t}\right)^{2}\right)
$$

We will solve the model using nonlinear methods and these price adjustments costs will not drop out of the resource constraint as they would when using linearized solution methods. We will see below that how these adjustment costs are treated has an important impact on the results. 


\subsection{Equilibrium}

The notion of equilibrium considered here is an imperfectly competitive general equilibrium in which the markets for the final good, intermediate goods, labor, capital and government debt clear in each period. The model developed above admits a symmetric monopolistically competitive equilibrium. We start by defining a perfect foresight equilibrium.

Definition A perfect foresight symmetric monopolistically competitive equilibrium consists of a sequence of allocations $\left\{c_{t}, h_{t}, x_{t}, k_{t}, \lambda_{c, t}, \lambda_{k, t}, y_{t}\right\}_{t=0}^{\infty}$, a set of policies $\left\{R_{t}\right\}_{t=0}^{\infty}$, a sequence of prices $\left\{r_{t}, w_{t}, \chi_{t}, \pi_{t}\right\}_{t=0}^{\infty}$ and a finite set of integers $I_{B}$ that satisfies the

- Households' optimality conditions

- Firms' optimality conditions

- Monetary policy rule:

- $\forall \mathrm{t} \notin I_{B}$ the zero constraint on interest rates is not binding and the Central Bank follows the Taylor rule (30)

$-\forall \mathrm{t} \in I_{B}$ the zero constraint on interest rates is binding and the Central Bank sets $R_{t}=0$

- Aggregate resource constraint and market clearing

given the initial conditions $\left(P_{-1}, R_{-1}, k_{0}\right)$, and sequences the exogenous shocks $\left\{A_{t}, d_{t}, \tau_{k, t}, \tau_{c, t}, \tau_{w, t}, g_{t}\right\}_{t=0}^{\infty} .^{2}$

Two points are worth mentioning. First, the definition of equilibrium is sequential. Second, the definition of equilibrium includes a statement of specific intervals where the zero lower bond on the nominal rate is binding.

\section{Solution Method and Calibration}

\subsection{Solution Method}

Our choice of solution method has three motivations. First, we choose a nonlinear solution method because recent research by Braun and Waki (2009) has found that modeling the nonlinearities associated with an occasionally binding zero lower bound can have a big impact on the size of the government purchase multiplier when the nominal interest rate hits its lower bound of zero. We will report results below that show that nonlinearities also

\footnotetext{
${ }^{2}$ Because we assume that the government adjusts lum-sum taxes such that its budget constraint is satisfied, we omit the government budget constraint from the equilibrium conditions and we omit government bonds and transfers from the list of variables determined in equilbrium.
} 
matter for the qualitative properties of the model such as the sign of the response of output to a shock in the labor tax.

The second motivation for our choice relates to finding the interval when the nominal interest rate is zero. Braun and Waki (2006) consider the problem of computing an equilibrium for an economy similar to ours in a perfect foresight setting. They limit attention to equilibria of the form where the interest rate is zero for only one finite and contiguous number of periods. Even with this restriction they find that there can be multiple equilibria and they impose two further equilibrium selection devices. First, they impose the restriction that the nominal interest rate in the model hits zero in a specific year that is dictated by Japanese data. Second, they select the equilibrium where the nominal interest rate is zero for the shortest interval of time. We use the same strategies for selecting an equilibrium here.

Third, we want to relax the perfect foresight assumption. When solving the model under perfect foresight one must specify the entire sequences for all exogenous variables. Then in time zero agents observe these sequences when making their decisions.

These three considerations led us to use a variant on a technique called extended shooting. ${ }^{3}$ Starting from the initial period, agents solve the set of nonlinear equations that describe their respective decision rules forward for 100 periods. We assume that our economy is at its steady state in period 101. In these future periods, shocks are set to 0 . We then move time forward by one period. Agents experience a new set of shocks and have a new set of initial conditions. They once again solve forward for 100 periods. This is repeated for each year from 1988 to 2007.

Because our solution method is sequential, we can limit the problem of dealing with the zero bound constraint to a small set of periods. Prior to 1999, households assign zero probability to the constraint binding in equilibrium. In the periods where households anticipate or experience a binding constraint we solve the model by hand using guess and verify methods to find the interval where the nominal interest rate is zero.

The principal limitation of this approach is that expectations about the future in any given period are degenerate. However, this solution strategy also highlights a hard problem. We know from previous research that the dynamics of the New Keynesian model can change in first order ways when the nominal interest rate is zero. Thus any solution method that allows for non-degenerate expectations formulation will probably require that agents form state dependent probabilities over the interval that the nominal interest rate constraint binds.

\footnotetext{
${ }^{3}$ Heer and Maussner (2008) provide an excellent description of the extended shooting algorithm
} 


\subsection{Calibration of Parameters}

We calibrate the parameters of our economy by matching model variables to calibration targets in Japanese data between 1981 and 2007. Recently, Bayesian estimation has become popular for parameterizing models like ours. But Bayesian estimation relies on a linearized system. Here the focus is specifically on nonlinear dynamics and estimation techniques that rely on linear time-series methods don't work in the presence of occasionally binding zero interest rate constraints. One could in principal estimate the model parameters using an earlier sample period when the nominal interest rate is positive. However, previous research by e.g. Chen, Imrohoroglu and Imrohoruglu (2006) and Braun, Ikeda and Joines (2009) show that Japan was undergoing large transitional adjustments between 1960 and 1990. This was the period of Japan's growth miracle and it is difficult to derive a stationary representation in the presence of large one off transitional dynamics induced by e.g. a low capital stock.

Table 1 reports the parameterization of our model. Most parameter choices closely resembles parameterizations elsewhere in the literature. The data used for the calibration is an updated version of the data employed by Hayashi and Prescott (2002). ${ }^{4}$ Most of the parameters are computed using averages from Japanese data over the sample period 1981-2007. The capital share parameter $\alpha$ is calibrated to match capital's share of income. The depreciation rate $\delta$ reproduces average depreciation in Japanese data. The steady state nominal rate is the average of the Japanese overnight call-rate. The coefficients for the law of motion of the taxes on labor and capital are estimated using Japanese data on average tax rates for these two variables. The coefficient governing the law of motion of governments share of output is estimated in the same manner. The weight on leisure in the utility function, $\nu$, is calibrated to match the average labor input between 2000 and 2007. We choose this period because prior to 2000, labor input exhibits a significant downward trend.

Other parameters are set in a more informal way. The parameter controlling the size of adjustment costs on investment is set to 4 . For purposes of comparison Braun and Waki (2006) use a value of 2 and Christiano, Eichenbaum and Rebelo (2006) use a value of 3. Using a high value of this parameter acts to increase the size of the government purchases multiplier. We will show below that even with such a choice its value is typically low.

The preference discount factor $\beta$ is set to 0.995 , a rather high level for a model with annual data. This choice implies that the steady state nominal interest rate of $2.9 \%$ is associated with a steady state inflation rate of zero. We set the curvature parameter in preferences to 2. The average markup is set to 15 percent as in Braun and Waki (2006), pinning down the value of the subsidy as 1.15 . We assume that technology, $A_{t}$, advances at a rate of $2 \%$ per annum.

The coefficient on inflation, $\rho_{\pi}$, and the lagged nominal rate in the Taylor rule, $\rho_{R}$, are set

\footnotetext{
${ }^{4}$ We wish to thank Nao Sudou of the Bank of Japan for providing us with the data.
} 
to 1.7 and 0.4 respectively. The adjustment cost parameter $\gamma_{0}$ is set to 80 . These parameter choices imply that the nominal rate increases on impact by $0.4 \%$ in response to a $1 \%$ shock to monetary policy. This response is a bit lower than the response of $0.6 \%$ estimated by Sugo and Ueda (2006) for the Japanese economy.

Finally, we start simulating our economy from 1987 and set the initial capital stock in our economy to the same value as its counterpart in Japanese data in 1987.

\subsection{Calibration of Shocks}

Our calibration strategy as described so far neither pins down values of the shock to the preference discount rate nor to the consumption tax or monetary policy. We now describe how we set these innovations.

We started by simulating our economy using the parameterization described above setting the shocks on the consumption tax, the preference discount rate and monetary policy to zero in all periods. That economy preformed reasonably well in terms of its implications for most real variables. However, the model did not produce a large secular decline in labor input after 1987. Between 1987 and 1991, there were some important institutional changes in labor market arrangements in Japan. The number of national holidays were increased and the length of the work week was reduced. In addition, the composition of the labor force changed. Miyazawa (2010) shows that the decline in labor input can partially be attributed to the increase in part-time work. We do not model these factors and instead treat them as altering the labor wedge. It is known from research by Kobayashi and Inaba (2006) that the labor wedge plays an important role in accounting for Japan's Business cycles.

By appropriate choice of the shocks to $\tau_{c, t}$ in the years 1987 to 1991 we can reproduce the movements in labor input during this period. The results from this parameterization are reported in Figure 1.

Inspection of this Figure indicates that the model does a reasonable job of reproducing some of the basic secular movements in the real side of the Japanese economy. It captures the capital deepening that occurred between 1990 and 2007. The model also captures the decline in output and consumption relative to their trends. As expected, the model does not reproduce labor input. In addition, the decline in the nominal rate and inflation is small and in particular the model does not produce a period of zero nominal interest rates.

Shocks to the preference discount rate play an important role in inducing a period of zero nominal interest rates in the work of Eggersston and Woodford (2003), Taehun, Teranishi and Watanabe (2005) and Christiano Eichenbaum and Rebelo (2009). We follow their approach and introduce shocks the preference discount factor. But shocks to $d_{t}$ take away with one hand what they give with the other: They make the zero lower bound binding but they also cause a deterioration in the fit for GNP and labour input. To counteract the stimulative effect that shocks to the preference discount rate have on these variables, we introduced 
simultaneous variations in the labor wedge by shocking $\tau_{c, t}$. With some experimentation we found that using a fixed factor of 5 works well.

Preference discount rate shocks produce counterfactually low inflation in the second half of the 1990s, too. To counteract the deflationary pressure due to these shocks, we introduced negative monetary policy shocks in the late 1990s. In our economy, a negative shock to monetary policy lowers the nominal interest rate and increases the inflation rate. In other research Sugo and Ueda (2006) have found that negative monetary policy shocks are important for understanding the Japanese economy in this period.

This calibration scheme resulted in the following sequence of shocks for $d_{t}$ : For 1993 to $1995,2 \%, 1 \%$, and $1 \%$, respectively and for $1999,2 \%$. This final shock makes the zero lower bound bind in 1999. In 1999 the value of the discount rate implied by the above shocks is 4.4 .

Throughout, the shock to $\tau_{c, t}$ which works primarily as a labor wedge is set to be five times the size of the $d_{t}$ shock. ${ }^{5}$ The shocks to monetary policy are $-0.5 \%$ in the years 1993 , 1996 and 1998 and $-1 \%$ in 1997.

These shocks bring the nominal interest rate and the inflation rate down in the 1990s and in particular get the nominal interest rate to hit its lower bound of zero in 1999. However, once the nominal interest rate is zero we were left with a question of how to handle the episode of zero nominal interest rates. In our baseline specification, we assume that in each period between 1999 to 2005 households expect that the nominal interest rate will be zero for two years. This assumption is based on evidence reported in Ichiue and Ueno (2007). They find using an affine model of the yield curve that the maximum expected duration of zero nominal interest rates during this period was 2.3 years. In 2006, the nominal rate is zero in the current period but agents expect positive nominal interest rates for 2007 and beyond. The Bank of Japan ended its zero nominal interest rate policy in March of 2006 and raised the call rate to 0.25 later in 2006 .

The sequence of shocks to $d_{t}$, that produces these expectations forecasts gradually declines from $0.3 \%$ in 2000 to $-0.25 \%$ in 2006 . We adjust $\tau_{c, t}$ to offset the implications of these shocks for labor input and output in the way described above. ${ }^{6}$

The results from the baseline simulation are reported in Figure 2. A comparison of Figure 2 with Figure 1 has the following noteworthy features. The shocks we have added after 1991 achieve the desired goal of bringing inflation and the nominal rate down during the second half of the 1990s. Moreover, the level of inflation during the period of zero nominal interest rates is about of the same level as we observe in Japanese data.

Relative to Figure 1, there is some deterioration in the fit of the model for real alloca-

\footnotetext{
${ }^{5}$ Formally, $\tau_{c, t}$ also affects the intertemporal first order condition. However, in our experience this effect is quantitatively very small.

${ }^{6}$ If we do not counteract a shock to the preference discount rate in e.g. 1999, agents expect positive nominal rates in 2000 instead of 2001.
} 
tions. The baseline economy understates consumption and overstates the extent of capital deepening. The reason for these changes in the fit of the model for real variables is the preference shock. On the one hand, a $d_{t}$ shock brings the nominal rate down but it also stimulates current labor input and output. We compensate for these effects using a shock to $\tau_{c, t}$. This improves the fit for these variables but also induces households to consume less and save more.

Overall, the baseline model does a good enough job of capturing the main features of Japan's experience between 1990 and 2007 to warrant using it as a laboratory for conducting counterfactuals.

The number of periods that agents expect the nominal interest rate to be zero can have a big effect on the properties of the model. To illustrate this point we will also report results for two other specifications. In the persistent expectations specification, the sequence of preference shocks hitting the economy between 1999 and 2007 is set so that agents expect zero nominal rates for 5 years in each of the years from 1999 to 2003. After 2003, agents expect that the nominal rate will become positive sooner. The nominal rate becomes positive in 2007. To implement this scenario, a shock to the preference discount rate of size $3 \%$ hits the economy in 1999. From 2000 to 2007, the size of preference discount rate shocks ranges between $0.6 \%$ and $-0.6 \%$.

In the large preference shock specification, we assume that the preference discount shock arriving in 1999 is equal to $4 \%$, a size sufficient to make agents expect in each year from 1999 to 2004 that nominal rates will be zero until 2005. They experience a binding zero lower bound until 2007. After 1999, no other shocks to $d_{t}$ or $\tau_{c, t}$ arrive.

\section{New Keynesian Dynamics in a Low Interest Rate En- vironment}

\subsection{Dynamic Responses of the Baseline Economy}

We now turn to analyze the dynamics of the our New Keynesian model. Previous research by Braun and Waki (2006), Christiano, Eichenbaum and Rebelo (2009) and Eggertsson (2009) have that the dynamic properties of the New Keynesian model are quite different when the nominal interest rate is zero. Using our model we can investigate the quantitative relevance of these effects for the Japanese economy during its episode with zero nominal interest rates.

Before discussing the results we wish to emphasize that output in our model differs from GNP. Measured GNP does not include costs of price adjustment. GNP for our economy is:

$$
G N P_{t} \equiv c_{t}+g_{t}+x_{t}=y_{t}\left(1-\frac{\gamma_{0}}{2}\left(\pi_{t}-\gamma_{1, t}\right)^{2}\right)
$$

. The distinction between production $y_{t}$ and GNP plays an important role in the analysis. 
For some specifications the difference between these two variables is large and shocks can have a big impact on the resource costs of price adjustment.

Table 2 reports results for the baseline specification. The first row shows the year being considered. The second row reports the number of years that agents expect the nominal interest rate to be zero. The third row reports the resource costs of price adjustment as percent of GNP. The remaining rows report impact responses of model GNP, production the markup to a variety of shocks.

Consider next the responses of GNP. Results are reported for permanent and transitory shocks to technology, shocks to the labor tax rate and shocks to government purchases. In all instances, the sign of the shock is positive. For the first three variables, the responses are percentage responses of GNP to a 1 percent impulse in the variable that is shocked. For the shock to government purchases we report $\frac{\Delta G N P}{\Delta G}$ and also $\frac{\Delta Y}{\Delta G}$. Results are reported for shocks that arrive in 1995, which is representative of years in which the current nominal interest rate is positive and expected nominal interest rates are positive in all future years. We also report impulse responses for shocks that arrive in 1999 and 2004. Responses reported for the years 1999 and 2004 differ in that in 1999 none of the shocks affects the equilibrium number of periods that the expected nominal interest rate is zero. In all cases agents continue to expect the nominal interest to be zero for two periods and then positive thereafter. In 2004 , in contrast some of the shocks reduce the expected number of periods of zero nominal interest rates by one period.

Observe first that the impulse responses of GNP and production to a shock in government purchases are very similar in magnitude in each of the three years. One reason for this finding is that the level of the resource costs of price adjustment is moderate, $0.63 \%$ of GNP. In other specifications reported below, the difference between these two variables will be more pronounced.

Observe next that Table 2 indicates that the dynamic responses of GNP in our New Keynesian economy are very similar when the nominal interest rate is positive and when it is zero. The signs of the responses are in good accord with what standard economic theory predicts: GNP increases in response to a positive technology shock of either type and falls in response to an increase in the labor tax.

The magnitudes are also consistent with standard economic theory. The magnitude of the government purchase multiplier is less than one in all periods. In 1995 it is 0.62 , it increases to 0.86 in 1999 but never rises above 1 in any period. The output multiplier associated with government purchases is also less than one in all periods. With the exception of a transitory shock to neutral technology, the multipliers in 2004 are smaller than in 1999. The markup response is also smaller in 2004 for these same variables. After these shocks in arrive in 2004 agents expect positive interest rates in 2005. For shocks that arrive in 1999 agents continue to expect that the nominal interest rate will be zero both in 1999 and 2000. 
Note next that the markup response to each of the shocks is larger when the nominal rate is zero. Consider e.g a shock to government purchases: the size of the markup response in both 1999 and 2004 is about three times larger than in 1995. Similar increases in the size of the markup response can be observed for the other shocks.

What is the economic mechanism responsible for the approximately threefold increase in markup volatility? It is known from previous work by e.g. Khan, King and Wolman (2002) that optimal government policy in a model with imperfectly competitive intermediate goods markets is to smooth the dynamic response of the markup to shocks. Schmitt-Grohe and Uribe (2007) find that a monetary policy that stabilizes the price level is an effective way to achieve this objective. In the New Keynesian model prices have a close link to the value of the markup via the New Keynesian Philips curve and stabilizing prices acts to limit the size of the response of the markup to shocks to government purchases and other exogenous variables. In practice, a simple Taylor (1993) rule with a large inflation elasticity also works very well. Once the nominal interest rate is zero though, the Taylor rule is no longer operative and monetary policy ceases to stabilize the response of the markup to shocks. This is the mechanism triggering the larger markup responses in Table 2. However, what is noteworthy about Table 2 , is that the level of markup variability is very small. Increasing its variability by a factor of three only has small quantitative effects on the dynamic response of the economy to shocks.

The results reported in Table 2 for the period of zero interest rates are quite different from results that have been documented elsewhere in the literature. The value of the government purchase multiplier reported in Table 2 is low and in particular, less than one. Christiano, Eichenbaum and Rebelo (2009), in contrast, find that the government purchases multiplier is much larger than one when the nominal interest rates is zero. In addition, the sign of the output response to either type of technology shock is positive in Table 2. Braun and Waki (2006) and Christiano, Eichenbaum and Rebelo (2009) find that it is negative when the nominal interest rate is zero. Finally, output falls when the labor tax is increased in Table 2 during the period of zero nominal interest rates. Eggerstsson (2008) finds that output increases in this situation. On the one hand, the results reported in Table 2 are reassuring because they are consistent with standard theory. On the other hand, they are quite different from findings reported elsewhere in the literature. We now turn to discuss the reasons for these differences.

\subsection{Relating our Findings to the Existing Literature}

The difference between the results reported in Table 2 and results reported elsewhere in the literature can be explained by three principal factors: The solution method; Household expectations about the duration of the period of zero nominal interest rates and; The size of the shock. 
Braun and Waki (2009) find that the choice of solution technique can have a big impact on the resulting size of the government purchase multiplier when the nominal interest rate is zero. Braun and Waki (2006) and Christiano, Eichenbaum and Rebelo (2006) use linear approximations to true decision rules when solving their models. In both papers, steady state price adjustment costs are zero. Linearizing the model equilibrium conditions has the effect of removing adjustment costs from the resource constraint. The linear approximation works well for small shocks but not for big shocks. We will show next that how adjustment costs are treated in the resource constraint has a big impact on the dynamic properties of our economy.

Table 3 reports impulse responses for different specifications of our economy. We assume that the shocks arrive in 1999 which is the year that the nominal interest rate first hits zero.

The first two columns of Table 3 report impulse responses for the baseline specification. In 1999 this specification is hit with a $2 \%$ shock to $d_{t}$ and a shock to $\tau_{c, t}$ of size 0.1 . This second shock has a small effect on the interest rate but a very large effect on the responses of hours and output. Recall that these shocks have the property that households expect the nominal interest rate to be zero for two periods. For purposes of comparison, column 1 repeats the baseline responses reported in Table 2. The second column reports responses for baseline specification when the costs of price adjustment are omitted from the resource constraint. For shocks of this size the resource costs of price adjustment are small and the responses are very similar in the two cases.

The next two columns report responses for the persistent expectations specification. For this specification in 1999 there is a $3 \%$ shock to $d_{t}$ and a simultaneous $0.15 \%$ shock to $\tau_{c, t}$. Consider first the results reported in column 3. The larger preference shock in 1999 has two effects: First, it lowers the shadow price of the nominal interest rate in 1999 and secondly, it increases the number of periods agents expect nominal rates to be zero from two years to five years. This combination of shocks induces a much larger response in the markup as compared to the baseline specification. Notice also that the resource costs are much larger here. The government purchases GNP multiplier increases to 1.35 which is about 60 percent larger than its value in the baseline specification. However, the multiplier for production is only moderately larger and still less than 1. Most of the boost in GNP is coming from a reduction in resource costs.

Expectations also play an important role. Although not reported in Table 3, the value of the GNP government purchases multiplier is also of about the same magnitude in 2000, a year in which there are no shocks to $d_{t}$.

Consider in turn the response of GNP to a permanent technology shock. The response continues to be positive and is also larger than the baseline response reported in column 1 . However, the magnitude of the increase as compared to the baseline response is small even though the markup response to this shock has more than doubled. 
What is the mechanism responsible for these results? The preference discount rate shock causes strong deflationary pressure in 1999 and this increases the cost of adjusting prices. Notice that the size of these resource costs is significant, $2.3 \%$ of GNP for this specification.

In our economy, both a positive government spending shock and a positive permanent technology shock act to decrease the markup and increase the inflation rate, thus attenuating the costs of price adjustment. This leaves more output available for consumption and investment which implies in turn a larger GNP response. This effect is most pronounced for government purchases because this type of shock has a large positive effect on the price level.

The same reasoning accounts for the attenuated labor tax response in column 3 as compared to the baseline specification. A higher labor tax also increases the price level and reduces the resource costs of price adjustment.

The opposite reasoning applies for the transitory shock to technology. A positive, transitory shock to technology increases the markup and lowers prices, thereby increasing the resource costs of price adjustment. Consequently, the GNP response is smaller here as compared to the baseline specification.

Column 4 reports results for the persistent expectations economy without the costs of adjusting prices in the resource constraint. For shocks of this size we can start to observe some differences between the two specifications of the resource constraint. Relative to column 3 , a positive, transitory shock to technology or a negative shock to the labor income tax increases GNP by less. The GNP government purchases multiplier increases to 1.45. Most significantly, the markup response is much larger for all types of shocks when the price adjustment costs are omitted from the resource constraint.

Finally, consider the results reported in columns 5 and 6 under the heading large preference shock. In this specification $d_{t}=0.04$ and $\tau_{c, t}=0.2$ in 1999. When the resource costs of adjustment are reflected in the budget constraint we find that the GNP government purchase multiplier is 1.75 . The output multiplier government purchase multiplier though is still less than one. GNP continues to respond in a conventional way to impulses to either form of technology shock or the labor tax shock. The picture changes dramatically though when the resource costs of price adjustment are omitted from the resource constraint. The response of the markup to any form of shock is now many orders of magnitude larger. The government purchases multiplier increases to 2.03 and the sign of the responses of GNP to innovations in transitory technology and labor taxes is now anomalous. As in Eggertsson (2009), output responds positively to an increase in labor income taxes. As in Christiano, Eichenbaum and Rebelo (2009) and Braun and Waki (2006) positive, transitory shocks to technology lower GNP.

Looking across these results we see that the "anomalous" responses of GNP to shocks to the labor tax or to transient shocks to technology that have been documented in the 
previous literature also arise in our economy if the costs of price adjustment are omitted from the resource constraint and if the size of the shocks to preferences are very large.

One remaining distinction between the results reported in Table 3 and the other literature pertains to the size of the government purchase multiplier. In particular, the size of the GNP government purchase multiplier in the final column of Table 3 is about 2. Christiano, Eichenbaum and Rebelo (2009), in contrast, report a value of about 4.

Braun and Waki (2009) consider a similar specification and experiment to the one considered in Christiano, Eichenbaum and Rebelo (2009). They find that the multiplier drops from 4 for the linearized solution to about 2.5 when an exact nonlinear solution is computed using Rotemberg (1996) costly price adjustment. ${ }^{7}$ These other two papers compute impulse responses for their models use the steady state as the initial condition and use only a preference discount rate shock to drive the nominal interest rate to zero. ${ }^{8}$ If we apply the same procedures to our model a $7 \%$ shock to the discount rate produces a government purchases GNP multiplier of 1.8 when the resource costs of price adjustment are ignored. The remaining gap between our multiplier of 1.8 and the multiplier of 2.5 reported in Braun and Waki (2009) is due to differences in the particular experiment that is considered. Braun and Waki (2009) set the government purchases to a high level for a fixed number of periods and the parameterization of the model. The parameterization of the Taylor rule plays a particularly important role. We allow for serial correlation in the nominal interest rate and Braun and Waki (2009) and Christiano, Eichenbaum and Rebelo (2009) set it to zero. One needs a substantially bigger shock to bring the nominal interest rate to zero when the nominal interest rate is serially correlated.

\subsection{Policy Counterfactuals}

In the introduction we asked the following three questions about Japan's episide with zero nominal interest rates:

1. How big was the government purchases multiplier?

2. Would a lower labor tax have depressed economic activity?

3. Did the slowdown in the growth rate of TFP raise GNP?

The results reported in Table 2 and 3 provide one set of answers to these questions. The results reported in those tables suggest that the answer to the second and third questions

\footnotetext{
${ }^{7}$ Christiano, Eichenbaum and Rebelo (2009) consider Calvo price adjustment. But, the linearized system for Calvo and Rotemberg price adjustment costs is identical when the parameters for price adjustment are chosen in the suitable way.

${ }^{8}$ Christiano, Eichenbaum and Rebelo (2009) consider a $5 \%$ shock to the discount factor. Braun and Waki (2009) consider a $4.5 \%$ shock to the discount factor.
} 
is no. The answer to the first question ranges between 0.9 and 1.5 depending on the specification of expectations. A limitation of the results reported in those tables is that they correspond to small changes in each exogenous variable. We now consider the following specific counterfactual simulations that are meant to illustrate how alternative sequences of empirically relevant shocks would have altered economic outcomes in Japan between 1999 and 2004. Table 4 reports results for four counterfactuals for the baseline and persistent expectations specifications. The first counterfactual considers how GNP growth would have changed between 1999 and 2004 if government purchases had experienced a sequence of shocks of equal size in each period that raised government purchases by on average about $2 \%$ per year. For the baseline specification this sequence of shocks to government purchases adds $0.2 \%$ per year to GNP growth. The corresponding value of the GNP government purchase multiplier is 0.64 . For the specification with persistent shocks to expectations GNP growth increases by $0.4 \%$ per year and the GNP multiplier is 1.12 .

In the second counterfactual we increase the growth rate of technology by $1 \%$ per year over the same interval using permanent shocks to technology that are of the same size in each year. This results in higher GNP growth of about 1\% per year for both specifications.

In the third counterfactual we consider what would have happened if there had been a sequence of positive transitory shocks to technology of equal size that averaged $0.8 \%$ per year. These shocks also increase GNP growth for either specification.

Finally, we ask how GNP in the Japanese economy might have changed if the labor tax rate had been lowered on average by $0.8 \%$ per year using equally sized shocks. From Table 5 we can see that this counterfactual increases GNP growth by about $1 / 2$ of one percent per year in both specifications.

The results based on these counterfactuals is consistent with the results based on the impulse response functions. The New Keynesian model has orthodox predictions regardless of whether the zero interest rate bound is binding or not.

\subsection{Implications of the Model for Volatility}

Results reported in the previous sections indicate that the GNP government purchase multiplier is larger than one if preference shocks are sufficiently large. Large preference shocks have implications for the volatility of GNP and other aggregate variables. We now turn to document how the implications of the model for volatility statistics vary with the size of the preference shocks and how these properties of the model line up with Japanese data.

Table 5 reports the standard deviation from 1988 to 1998 relative to the standard deviation between 1999 and 2007 for Japanese data and alternative specifications of the model. A relative volatility statistic of less than one means that the respective variable was less volatile during the period of zero nominal interest rates.

The first row of Table 5 reports relativity statistics for Japanese data. Observe that the 
period of zero nominal interest rates was a period of tranquility. The relative volatilities of GNP, consumption, real marginal cost and inflation are all well less than one. ${ }^{9}$ Technological growth has become more resilient in the zero interest rate period, too, providing at least a partial explanation for the relative tranquility of the Japanese economy with nominal rates at zero. Labor input is the only variable that is more variable during the 1998-2007 sample period.

Notice next that the baseline specification successfully reproduces the low relative volatility observed in Japanese data. For purposes of comparison we also report results for specifications with lower adjustment costs on prices $\gamma_{0}=10$ and a version of the model with flexible prices. ${ }^{10}$ All three of these specifications use the same sequence of shocks. Notice that all three specifications successfully reproduce basic pattern of low volatility found in Japanese data.

Consider in turn the specification with persistent expectations. Recall that this specification calibrates the preference shocks to induce expectations of zero nominal interest rates of 5 years in each period between 1999 and 2004 and produces a GNP government purchases multiplier of 1.35 in 1999. This specification predicts that the period of zero nominal interest rates should have been a period of relatively large volatility which is not what actually happened in Japan.

In the final row we report relative volatility for the large preference shock specification. This simulation assumes that there is one large shock in 1999 and that the shocks to $d_{t}$ and $\tau_{c, t}$ are zero in other periods after 1999. The large preference shock specification also predicts that Japan's episode with zero nominal interest rates should have been a period of large economic volatility. Albeit not reported in Table 5, we have also calculated the volatility of the large preference shock specification without the costs of adjusting prices in the resource constraint, too. The volatility of the shocks is identical whether or not price adjustment costs are taken into account in the resource constraint. The volatility of endogenous variables, is much higher in the economy without price adjustment costs in the resource constraint.

Overall, the results reported in Table 5 suggest that it may be hard to reconcile the large shocks specifications that produce government purchase multipliers greater than one with Japan's episode with zero nominal interest rates.

\footnotetext{
${ }^{9}$ We follow Muto (2009) and use a labor share measure of real marginal costs that accounts for employees in self-employed firms. Therefore, we calculate real marginal costs as $\frac{1}{\alpha}$ Compensation of employees/(National income - households' operating surplus)

${ }^{10}$ For the flexible price model we do not impose the zero bound constraint
} 


\subsection{Robustness}

In this section, we briefly describe the robustness of our conclusions to the choice of the parameterization and the choice of the preference shock processes.

One of the key parameters in our calibration is the magnitude of the price adjustment cost parameter. Table 4 compares volatilities generated by an economy with a more moderate adjustment cost parameter of 10 with volatilities generated by our baseline economy when hit by the same sequences of shocks. While they predict similar volatilities for GNP, consumption and labor input, the model with lower costs of price adjustment creates a higher volatility of real marginal costs and inflation that is closer to the volatility observed in Japanese data.

The dynamic responses for the economy with a low value for the parameter governing the costs of price adjustment, $\gamma_{0}=10$ are similar to results reported in Table 2 for the baseline specification. Under the baseline assumption that agents expect zero nominal rates for two years in each year from 1999 to 2005, we find a GNP government purchases multiplier in 1999 equal to 0.79 , which is close to the value of 0.86 for the baseline economy. The responses of GNP to other shocks are also very similar to the baseline responses.

The qualitative nature of our results is also robust to the parameterization of the Taylor rule. We have obtain qualitatively similar results using Taylor rules that set the coefficient on the lagged value of the nominal rate to zero or use a different coefficient on inflation.

Turning to the choice of the shock processes we wish to first mention that our assumption that technology follows a unit root process does have an impact on some of our results. Under our current assumption that shocks to technology are permanent agents best guess of tomorrow's state of technology is today's state of technology plus drift, the past is of no help for them for the purpose of forming expectations about the future. Technology shocks play a big role in the dynamics of the model and under this assumption agents never expect the zero lower bound to bind in advance of 1999. If instead technological progress is deterministic and shocks to technology are auto-correlated agents start to predict zero nominal interest rates several years before the nominal interest rate falls to zero and this acts to change the dynamics of the model before the nominal interest rate is zero. The dynamics start to change as soon as agents expect zero nominal rates in the future. This finding is significant in the sense that it is not necessary for the nominal interest rate to be zero in order for the dynamics of the model to start to shift. All that is necessary is that agents expect the nominal interest rate to be zero in the future.

Finally, we have also conducted simulations in which we kept the tax rate on the consumption constant. ${ }^{11}$ This leads to a deterioration in the fit of the model for GNP and labor input. However, the magnitudes of the GNP impulse responses and the GNP multiplier are

\footnotetext{
${ }^{11}$ Under this assumption a $3 \%$ shock to the discount factor is needed to induce a binding zero nominal 1999 that agents expect to last for two years.
} 
very close to those reported for our baseline specification.

\section{Concluding Remarks}

In this paper we have conducted a quantitative investigation aimed at assessing the dynamics of the New Keynesian model in a low interest rate environment.

We produced a baseline specification that does a reasonable job of reproducing some basic stylized facts from the Japanese economy between 1990 and 2007. An investigation of the dynamic properties of that specification implies that the response of GNP to a range of shocks is consistent with standard theory. Moreover, the size of the GNP government purchases multiplier is less than one.

We also produced specifications of the model that have orthodox predictions for the response of GNP to labor tax and technology shocks but generate a government purchase multiplier greater than one. These specifications require large shocks to preferences and this property is inconsistent with Japanese data. Japan's episode with zero interest rates was a relatively tranquil period with low variability of output, consumption, inflation and real marginal cost but these specifications imply that the period of zero nominal interest rates is one of relatively large economic volatility.

We have considered this question in an environment where agents receive new news about the state of the economy in each period and use this information to update their forecasts about future economic activity. A limitation of our analysis though is that those forecasts are degenerate and assign all probability to a single sequence of future outcomes. A valuable line of future inquiry would be to consider how to relax this restriction. 


\section{References}

[1] Basu, Susanto and Miles Kimball (2003) Investment Planning Costsand the Effects of Fiscal and Monetary Policy. Unpublished manuscript.

[2] Braun, R. Anton, Daisuke Ikeda, and Douglas H. Joines (2009), "The Saving Rate in Japan: Why I Has Fallen and Why It Will Remain Low," International Economic Review Vol. 50(1) 291-321.

[3] Braun, R. Anton, and Yuichiro Waki (2006), "Monetary Policy during Japan's Lost Decade" The Japanese Economic Review Vol. 57, No. 2, 324-344.

[4] Braun, R. Anton, and Yuichiro Waki (2009), "On the Fiscal Multiplier When the Zero Bound on Nominal Interest Rates is Binding," mimeo.

[5] Chen, Kaiji, A. Imrohoroglu and S. Imrohoroglu (2006), "The Japanese Saving Rate" American Economic Review 96(5), 1850-1858.

[6] Christiano, Lawrence, Martin Eichenbaum and Charles Evans, (2005) "Nominal Rigidities and the Dynamic Effects of a Shock to Monetary Policy," Journal of Political Economy, 113: 1-45.

[7] Christiano, Lawrence, Martin Eichenbaum, and Sergio Rebelo (2009), "When is the Government Spending Multiplier Large?" mimeo.

[8] Eggertsson, Gauti, and Michael Woodford (2003) "The Zero Interest Rate Bound and Optimal Monetary Policy." Brookings Panel on Economic Activity.

[9] Eggertsson, Gauti B. (2009), "Can a Tax Cut Deepen the Recession?" mimeo.

[10] Herr, Burkhard, and Alfred Maussner (2008), Dynamic General Equilibrium Modelling Springer Berlin Heidelberg New York

[11] Ichiue, Hibiki and Yoichi Ueno (2007) "Equilibrium Interest Rate and the Yield Curve in a Low Interest Rate Environment." Bank of Japan working paper.

[12] Kobayashi, Keiichiro and Masuru Inaba (2006) "Business Cycle Accounting for the Japanese Economy." Japan and the World Economy 18, 418-440.

[13] Khan, A., R.King, and A.Wolman (2002), "Optimal Monetary Policy," NBER Working Paper No. 9402.

[14] Miyazawa, Kensuke (2010) "Japan's Lost Decade and the Decline in Labor Input." Unpublished Manuscript. 
[15] Muto, Ichiro (2009). "Estimating a New Keynesian Phillips Curve with a Corrected Measure of Real Marginal Cost: Evidence in Japan", Economic Inquiry, 47(4), pp. 667-684.

[16] Rotemberg, Julio (1996), "Prices, Output and Hours: An Empirical Analysis based on a Sticky Price Model, Journal of Monetary Economics, 37, pp. 505-33.

[17] Schmitt-Grohe, Stephanie, and Martin Uribe (2007), "Optimal Simple and Implementable Monetary and Fiscal Rules," Journal of Monetary Economics 54, 1702-1725.

[18] Sugo, Tomohiro and Kozo Ueda (2006), "Estimating a DSGE Model for Japan: Evaluating and modifying a CEE/SW/LOWW Model", mimeo.

[19] Taehun, Jung, Yuki Teranishi and Tsutomu Watanabe (2005) "Optimal Monetary Policy at the Zero-Interest-Rate Bound," Journal of Money, Credit, and Banking 37 (5) pg. 813-835. 


\section{Technical Appendix}

\section{Balanced Growth Path}

The analogue economy developed above allows a balanced growth path. In turn, we characterize the balanced growth path.

Consider the perfect foresight balanced growth path

$$
A_{t} / A_{t-1}=Z_{A, t} / Z_{A, t-1}=\mu_{A}
$$

The aggregate resource constraint (29) implies

$$
\mu_{y}=\mu_{x}=\mu_{c}
$$

It follows from the equation (4) that

$$
\mu_{y}=\mu_{k}
$$

combining the production function for intermediate goods (12) with the two above restrictions yields:

$$
\mu_{y}=\mu_{k}=\mu_{A}
$$

Based on these results we can readily derive the growth rate of other variables along the balanced growth path. Here are the growth rates of some other variables:

$$
\begin{aligned}
& \mu_{r}=\mu_{k}^{\alpha-1} \mu_{A}^{1-\alpha}=1 \\
& \mu_{\lambda_{c}}=\mu_{y}^{\nu(1-\sigma)-1}=\left(\mu_{A}\right)^{\nu(1-\sigma)-1} \\
& \mu_{\lambda_{k}}=\mu_{\lambda_{c}}
\end{aligned}
$$

\section{Equilibrium Conditions of the Stationary Economy}

In this section, we use the properties of the balanced growth path perform the following stationary inducing transformations:

$\forall z_{t} \in\left\{y_{t}, c_{t}, x_{t}, k_{t}, g_{t}, w_{t}\right\}$, we define $\hat{z}_{t} \equiv z_{t} / Z_{A, t}$. In addition, we define $\hat{\lambda}_{c, t} \equiv$ $\lambda_{c, t} Z_{A, t}^{1-\nu(1-\sigma)}$ and the same transformation applies to $\lambda_{k, t}$.

$$
\begin{aligned}
& \left.\mu_{k, t} \hat{k}_{t}=(1-\delta) \hat{k}_{t-1}+\mu_{k, t} \hat{x}_{t}\right)-\frac{\phi}{2}\left(\mu_{k, t} \frac{\hat{x}_{t}}{\hat{k}_{t-1}}-\mu_{k}+1-\delta\right)^{2} \hat{k}_{t-1} \\
& \frac{\nu\left(\hat{c}_{t}^{\nu}\left(1-h_{t}\right)^{1-\nu}\right)^{1-\sigma}}{\hat{c}_{t}}=\hat{\lambda}_{c, t}\left(1+\tau_{c, t}\right)
\end{aligned}
$$




$$
\begin{aligned}
& \frac{(1-\nu)\left(\hat{c}_{t}^{\nu}\left(1-h_{t}\right)^{1-\nu}\right)^{1-\sigma}}{1-h_{t}}=\hat{\lambda}_{c, t}\left(1-\tau_{w, t}\right) \hat{w}_{t} \\
& \hat{\lambda}_{c, t}=\hat{\lambda}_{k, t}\left[1-\phi\left(\mu_{k, t} \frac{\hat{x}_{t}}{\hat{k}_{t-1}}-\mu_{k}+1-\delta\right)\right]
\end{aligned}
$$

Note that $\mu_{k}=\mu_{A}$ and $\mu_{k, t}=\mu_{A, t}$.

$$
\begin{array}{r}
0=\beta E_{t} d_{t+1} \hat{\lambda}_{c, t+1} \mu_{\lambda_{k, t+1}}\left[\left(1-\tau_{k, t+1}\right) \hat{r}_{t+1}+\tau_{k, t+1} \delta\right]-\hat{\lambda}_{k, t}+ \\
\beta E_{t} d_{t+1} \hat{\lambda}_{k, t+1} \mu_{\lambda_{k, t+1}}\left[\phi\left(\mu_{k, t+1} \frac{\hat{x}_{t+1}}{\hat{k}_{t}}-\mu_{k}+1-\delta\right) \frac{\hat{x}_{t+1}}{\hat{k}_{t}} \mu_{k, t+1}\right. \\
\left.\left.+1-\delta-\phi / 2\left(\mu_{k, t+1}\right) \frac{\hat{x}_{t+1}}{\hat{k}_{t}}-\mu_{k}+1-\delta\right)^{2}\right]
\end{array}
$$

where we use the definitions of $\mu_{\lambda_{c}}$ and $\mu_{\lambda_{c}}$ from above to simplify the expression.

$$
\begin{aligned}
& -\hat{\lambda}_{c, t}+\beta E_{t} \frac{\left(1+R_{t}\right)}{\left(1+\pi_{t+1}\right)} d_{t+1}\left(\mu_{A, t+1}\right)^{\nu(1-\sigma)-1} \hat{\lambda}_{c, t+1}=0 \\
& \beta E_{t}\left(\mu_{A, t+1}\right)^{\nu(1-\sigma)} \frac{d_{t+1} \hat{\lambda}_{c, t+1} \hat{y}_{t+1}}{\hat{\lambda}_{c, t} \hat{y}_{t}} \gamma_{0}\left(\pi_{t+1}-\gamma_{1, t+1}\right)\left(1+\pi_{t+1}\right)=-\left[1-\theta+\theta \chi_{t}-\gamma_{0}\left(\pi_{t}-\gamma_{1, t}\right)\left(1+\pi_{t}\right)\right] \\
& \hat{y}_{t}=\hat{k}_{t-1}^{\alpha}\left(h_{t}\right)^{(1-\alpha)} \mu_{A, t}^{-\alpha} \\
& \hat{r}_{t}=\alpha \chi_{t} \hat{k}_{t-1}^{\alpha-1} h_{t}^{1-\alpha}\left(\mu_{A, t}\right)^{1-\alpha} \\
& \hat{r}_{t} / \hat{w}_{t}=\frac{\alpha}{(1-\alpha)} \frac{h_{t}}{\hat{k}_{t-1}} \mu_{A, t} \\
& R_{t}=\max \left[R\left(\pi_{t}\right), 0\right] \\
& \hat{g}_{t}+\hat{c}_{t}+\hat{x}_{t}=\hat{y}_{t}\left(1-\frac{\gamma_{0}}{2}\left(\pi_{t}-\gamma_{1, t}\right)^{2}\right) .
\end{aligned}
$$




\section{Steady state Conditions of the Stationary Economy}

We conjecture a steadystate with a constant nominal interest rate $R$ and constant lump-sum transfers.

$$
\begin{aligned}
& {\left[\mu_{A}-(1-\delta)\right] \hat{k}=\mu_{A} \hat{x}} \\
& \frac{\nu\left(\hat{c}^{\nu}(1-h)^{1-\nu}\right)^{1-\sigma}}{\hat{c}}=\hat{\lambda}_{c}\left(1+\tau_{c}\right) \\
& \frac{(1-\nu)\left(\hat{c}^{\nu}(1-h)^{1-\nu}\right)^{1-\sigma}}{1-h}=\hat{\lambda}_{c}\left(1-\tau_{w}\right) \hat{w} \\
& \hat{\lambda_{c}}=\hat{\lambda}_{k} \\
& 0=\beta \mu_{\lambda_{k}}\left[\left(1-\tau_{k}\right) \hat{r}+\tau_{k} \delta\right]-1+\beta \mu_{\lambda_{k}}[1-\delta] \\
& \hat{g}+\hat{c}+\hat{x}=\hat{y}\left(1-\frac{\gamma_{0}}{2}\left(\pi-\gamma_{1}\right)^{2}\right) . \\
& \hat{1}+\pi \\
& \hat{r}=\alpha \chi \hat{k}^{\alpha-1} h^{1-\alpha} \mu_{A}^{1-\alpha} \\
& \hat{y}=\hat{k}^{\alpha} h^{(1-\alpha)}\left(\mu_{A}\right)^{-\alpha} \\
& \beta\left(\mu_{A}\right)^{\nu(1-\sigma)} \gamma_{0}\left(\pi-\gamma_{1}\right)(1+\pi)=-\left[1-\theta+\theta \chi-\gamma_{0}\left(\pi-\gamma_{1}\right)(1+\pi)\right] \\
& \left.\hat{k} u_{A}\right]
\end{aligned}
$$




\section{Steady state of the Stationary Economy}

This section solves for the steady state in closed form.

First, we use (53) to solve for $\pi$

$$
1+\pi=(1+R)\left[\beta\left(\mu_{A}\right)^{\nu(1-\sigma)-1}\right]
$$

Next, we use (54) to solve for $\chi$ :

$$
\chi=\frac{1}{\theta}\left[\theta-1+\gamma_{0}\left(\pi-\gamma_{1}\right)(1+\pi)-\beta\left(\mu_{A}\right)^{\nu(1-\sigma)} \gamma_{0}\left(\pi-\gamma_{1}\right)(1+\pi)\right]
$$

and use (52) to find $\hat{r}$ :

$$
\hat{r}=\left[\frac{1-\beta \mu_{\lambda_{k}}(1-\delta)}{\beta \mu_{\lambda_{k}}}-\tau_{k} \delta\right] \frac{1}{\left(1-\tau_{k}\right)} .
$$

We use (56) to solve for $h / \hat{k}$,

$$
\left(\frac{\hat{r}}{\chi \alpha \mu_{A}^{1-\alpha}}\right)^{\frac{1}{1-\alpha}}=\left(\frac{h}{\hat{k}}\right)
$$

and (57) to solve for $\hat{w}$ :

$$
\hat{w}=\left[\frac{\alpha}{(1-\alpha)} \frac{h}{\hat{k}} \mu_{A}\right]^{-1} \hat{r}
$$

Next (48) can be used to find $\hat{x} / \hat{k}$ :

$$
\frac{\hat{x}}{\hat{k}}=\frac{\left[\mu_{A}-(1-\delta)\right]}{\mu_{A}}
$$

and $(55)$ to find $\hat{y} / \hat{k}$ :

$$
\frac{\hat{y}}{\hat{k}}=\left(\frac{h}{\hat{k}}\right)^{(1-\alpha)}\left(\mu_{A}\right)^{-\alpha}
$$

Then the resource constraint can be used to find $\hat{c} / \hat{y}$ :

$$
\frac{\hat{c}}{\hat{y}}=\left(1-\frac{\gamma_{0}}{2}\left(\pi-\gamma_{1}\right)^{2}\right)-\frac{\hat{g}}{\hat{y}}-\frac{\hat{x}}{\hat{y}} .
$$

Then we can use (50) to find $h$. First,

$$
\hat{w}=(1-\alpha) \chi \frac{\hat{y}}{h}
$$

Next, we use the households' optimality condition for c, and divide it by the optimality condition for $\mathrm{h}$, 


$$
\frac{1-\nu}{\nu} \frac{\hat{c}}{1-h}=\frac{\left(1-\tau_{W}\right)}{\left(1+\tau_{c}\right)} \hat{w}
$$

Combining the previous two expressions,

$$
\frac{1-\nu}{\nu} \frac{\hat{c}}{1-h}=\frac{\left(1-\tau_{W}\right)}{\left(1+\tau_{c}\right)}(1-\alpha) \chi \frac{\hat{y}}{h}
$$

Then,

$$
h \frac{1-\nu}{\nu} \frac{\hat{c}}{\hat{y}}=\frac{\left(1-\tau_{W}\right)}{\left(1+\tau_{c}\right)} \chi(1-\alpha)(1-h)
$$

Solving for h yields:

$$
h=\frac{\frac{\left(1-\tau_{W}\right)}{\left(1+\tau_{c}\right)} \chi(1-\alpha)}{\frac{1-\nu}{\nu} \frac{\hat{c}}{\hat{y}}+\frac{\left(1-\tau_{W}\right)}{\left(1+\tau_{c}\right)} \chi(1-\alpha)}
$$

Given $h$ we can now solve for $k$ using equation (62). Given $k$ we can find $y$ from equation (65), $x$ from equation (64), and $c$ from equation (66). Finally, $\lambda_{c}=\lambda_{k}$ can be found from (49). 
Table 1: Model Parametrization

\begin{tabular}{|c|c|c|}
\hline Symbol & Value & Description \\
\hline$\alpha$ & 0.362 & Capital share \\
\hline$\delta$ & 0.085 & Depreciation rate \\
\hline$\phi$ & 4 & Adjustment costs on capital \\
\hline$\beta$ & 0.995 & Discount factor \\
\hline$\nu$ & 0.27 & Preference consumption share \\
\hline$\sigma$ & 2 & Adjustment costs on prices \\
\hline$\gamma_{0}$ & 80 & Steady state gross markup \\
\hline$\theta /(\theta-1)$ & 1.15 & Steady state nominal rate \\
\hline $\mathrm{R}$ & 0.029 & Steady state labor income tax \\
\hline$\rho_{R}$ & 0.4 & Elasticity of the nominal rate with respect to output \\
\hline$\rho_{\pi}$ & 1.7 & Elasticity of the nominal rate with respect to inflation \\
\hline$\tau_{w}$ & 0.27 & Steady state consumption tax \\
\hline$\rho_{w}$ & 0.9 & Autocorrelation coefficient of labor income tax \\
\hline$\tau_{c}$ & 0.05 & Steady state capital tax \\
\hline$\tau_{k}$ & 0.41 & Steady state government share \\
\hline$\rho_{k}$ & 0.9 & Autocorrelation coefficient of capital income tax \\
\hline $\mathrm{G} / \mathrm{Y}$ & 0.19 & Autocorrelation coefficient of government spending \\
\hline$\rho_{G}$ & 0.89 & Steady state growth rate of technology \\
\hline$\mu_{A}$ & 1.02 & Autocorrelation coefficient of consumption tax \\
\hline$\rho_{A}$ & 0.92 & Autocorrelation coefficient of transient technology shocks \\
\hline$\rho_{c}$ & 0.9 & \\
\hline & &
\end{tabular}




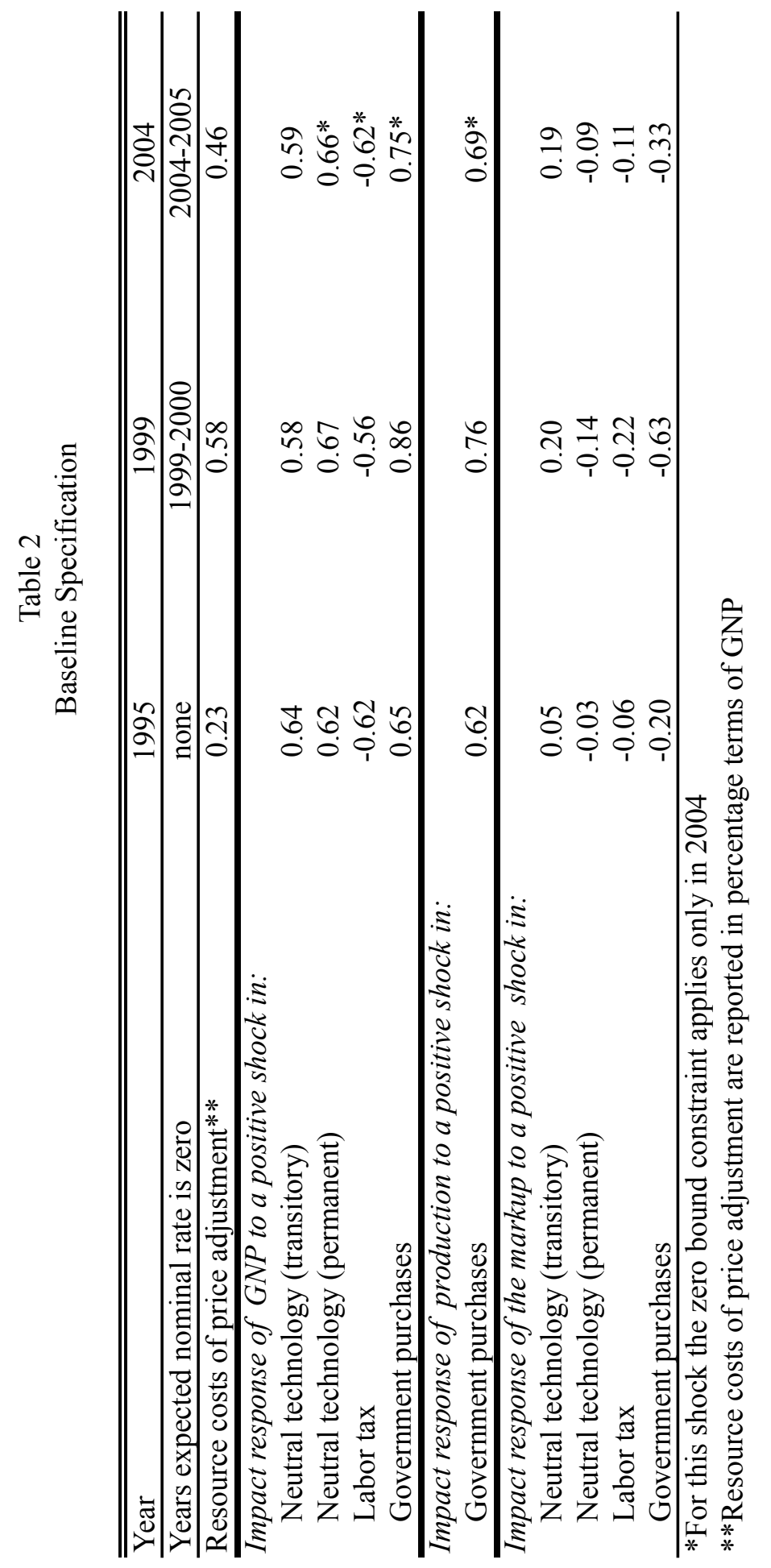




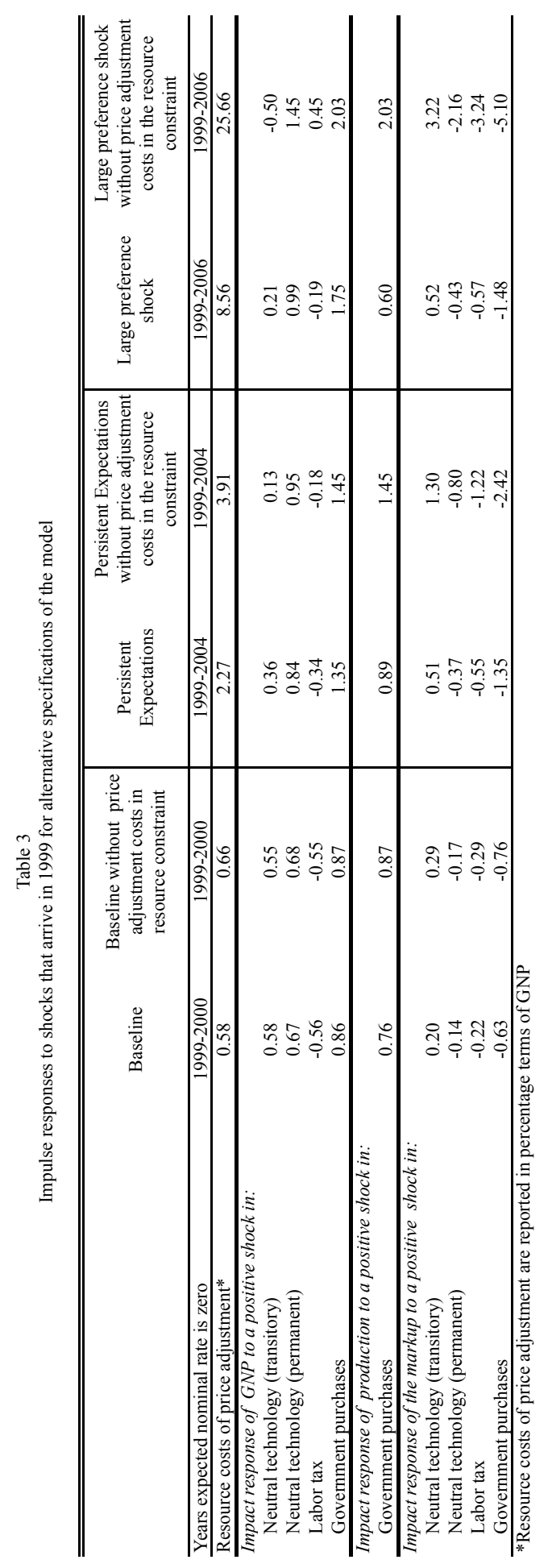




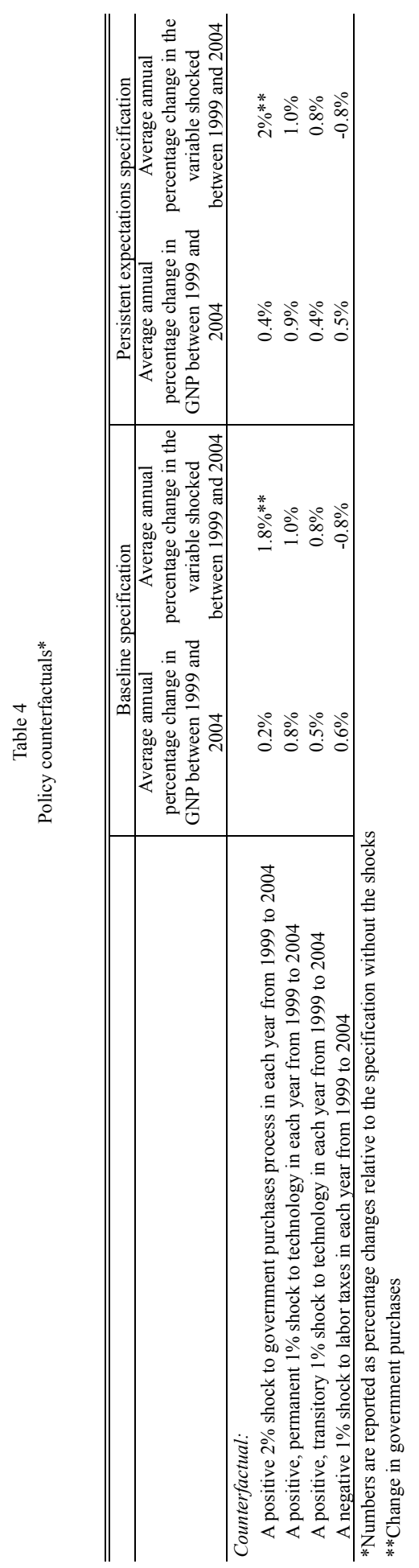




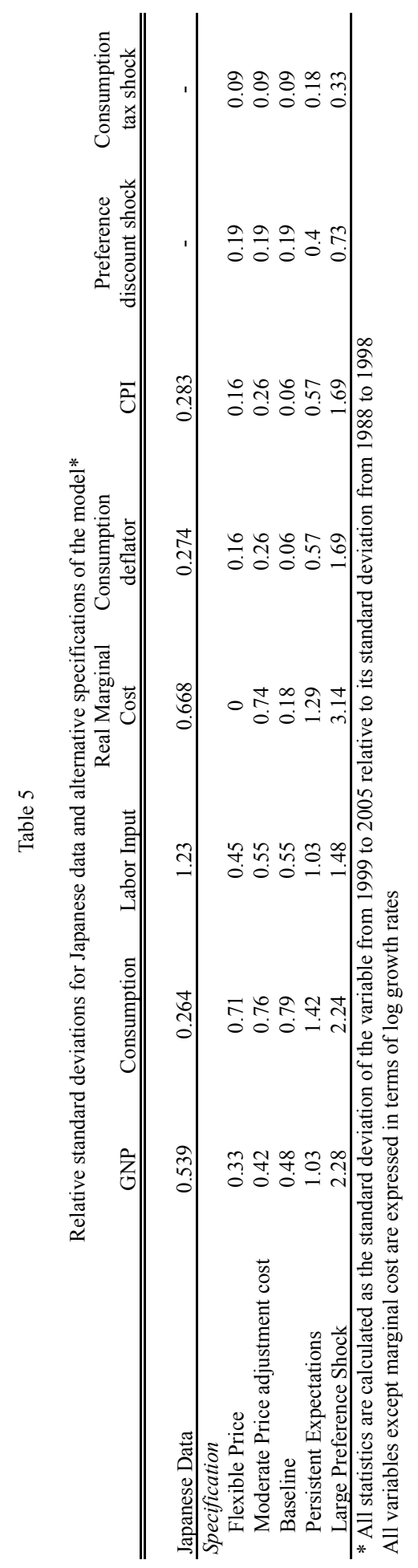



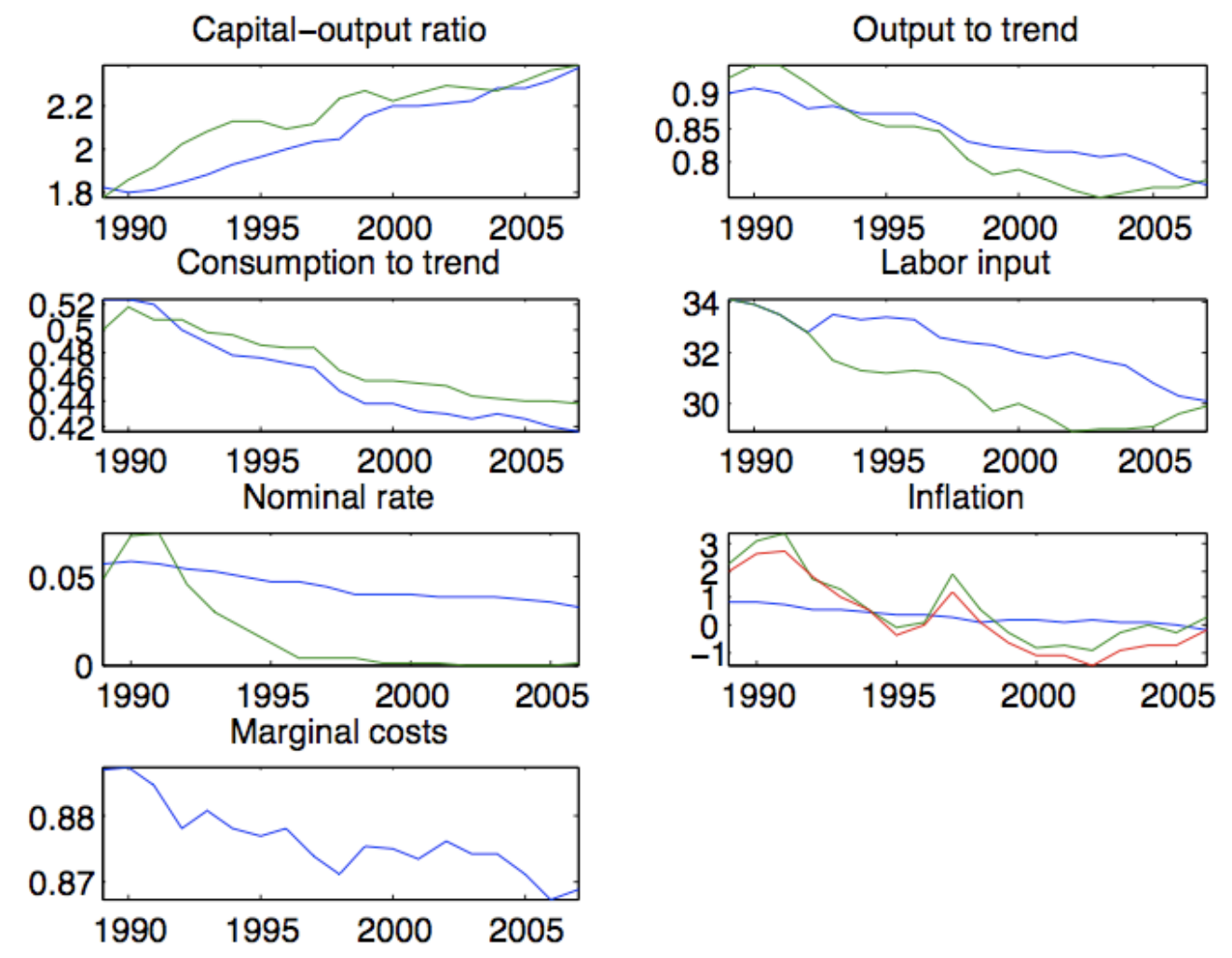

Figure 1: Baseline economy if neither preference nor monetary policy shocks arrive after 1991 

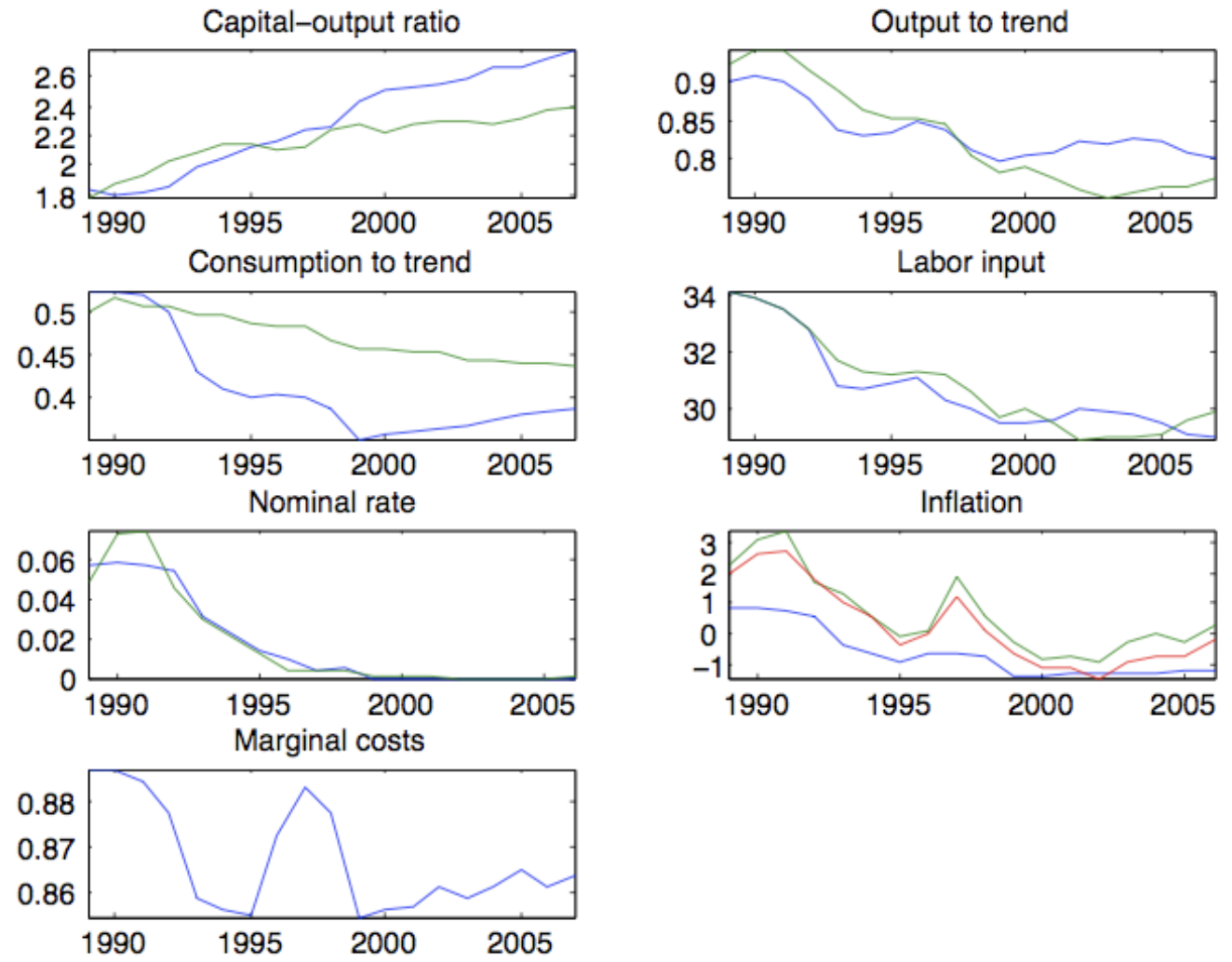

Figure 2: Baseline economy 